\title{
Physico-chemical characterization and source tracking of black carbon at a suburban site in Beijing
}

\author{
Hailin Wang ${ }^{1,2, *}$, Lei $\mathrm{Nie}^{1}$, Dan Liu ${ }^{3}$, Meiping Gao ${ }^{1}$, Minyan Wang ${ }^{1}$, Zhengping Hao ${ }^{4, * *}$ \\ 1. National Urban Environmental Pollution Control Engineering Techniques Research Center, Beijing Municipal Research Institute of Environmental \\ Protection, Beijing 100037, China. E-mail: wanghailin@cee.cn \\ 2. Jiangsu Key Laboratory of Atmospheric Environment Monitoring and Pollution Control, Nan-jing University of Information Science and Technology, \\ Nanjing 210044, China \\ 3. Department of Chemical Engineering, School of Chemical \& Environmental Engineering, China University of Mining \& Technology, Beijing 100083, \\ China \\ 4. Department of Environmental Nano-materials, Research Center for Eco-Environmental Sciences, Chinese Academy of Sciences, Beijing 100085, \\ China
}

\section{A R T I C L E I N F O}

Article history:

Received 22 September 2014

Revised 25 February 2015

Accepted 7 May 2015

Available online 15 May 2015

Keywords:

Black carbon

Characterization

Source emission

Beijing

\begin{abstract}
A B S T R A C T
Particles from ambient air and combustion sources including vehicle emission, coal combustion and biomass burning were collected and chemically pretreated with the purpose of obtaining isolated BC (black carbon) samples. TEM (transmission electron microscopy) results indicate that $\mathrm{BC}$ from combustion sources shows various patterns, and airborne $\mathrm{BC}$ appears spherical and about $50 \mathrm{~nm}$ in diameter with a homogeneous surface and turbostratic structure. The BET (Barrett-Emmett-Teller) results suggest that the surface areas of these BC particles fall in the range of 3-23 $\mathrm{m}^{2} / \mathrm{g}$, with a total pore volume of $0.03-0.05 \mathrm{~cm}^{3} / \mathrm{g}$ and a mean pore diameter of $7-53 \mathrm{~nm}$. The nitrogen adsorption-desorption isotherms are indicative of the accumulation mode and uniform pore size. $\mathrm{O}_{2}$-TPO (temperature programmed oxidation) profiles suggest that the airborne $\mathrm{BC}$ oxidation could be classified as the oxidation of amorphous carbon, which falls in the range of $406-490^{\circ} \mathrm{C}$ with peaks at 418,423 and $475^{\circ} \mathrm{C}$, respectively. Generally, the $\mathrm{BC}$ characteristics and source analysis suggest that airborne $\mathrm{BC}$ most likely comes from diesel vehicle emission at this site.
\end{abstract}

(c) 2015 The Research Center for Eco-Environmental Sciences, Chinese Academy of Sciences. Published by Elsevier B.V.

\section{Introduction}

Black carbon (BC) is usually defined as particles, black in color, and composed mostly of elemental carbon with oxygen and hydrogen as minor components. In most cases, BC comes from the incomplete combustion of fuel oil, coal, biomass and so on. Processes including nucleation, increase of surface area, accumulation, agglomeration and oxidation take place during the combustion before BC particles are emitted to atmosphere (Richter and Howard, 2000). During the past decades, BC has been released in increasing quantities into the atmosphere and dispersed over wide areas by long-distance transport (Cachier et al., 1988; Chylek et al., 1992; Rose, 1995). BC possesses characteristics different from those of other atmospheric

\footnotetext{
* Correspondence to: H. Wang, National Urban Environmental Pollution Control Engineering Techniques Research Center, Beijing Municipal Research Institute of Environmental Protection, Beijing 100037, China.

** Corresponding author. E-mail: wanghailin@cee.cn (Hailin Wang), zpinghao@rcees.ac.cn (Zhengping Hao).
} 
aerosols, and has been shown to absorb sunlight, heat the air, and contribute to global warming (Hansen et al., 2000; Jacobson, 2002; Menon et al., 2002). BC was found to strongly adsorb pesticides, polyaromatic hydrocarbons (PAHs), biphenyls (PCBs), polychlorinated dibenzo-p-dioxins (PCDDs) and so on (Lohrnann et al., 2002; Yang and Sheng, 2003a, 2003b; Yang et al., 2004). BC in accumulation mode with absorbed PAHs, heavy metals and other toxic matters could enter the human body by inhalation and threaten public health. In addition, BC also plays an important role in photochemical reactions, heterogeneous reactions and gas-to-particle conversion (Decesari et al., 2002).

Due to its significant impact on climate, public health and the environment, BC has been widely studied in terms of concentration measurement, optical properties, size distribution, climate forcing and so on. Since the 1990s, several large-scale international aerosol observation experiments have been carried out, such as ACE (Aerosol Characterization Experiment) (Alfaro et al., 2003), RACE (Radiative Aerosol Characterization Experiment) and INDOEX (the Indian Ocean Experiment) (Lelieveld et al., 2001). BC observation is regarded as an important component in these plans. In addition, continuous observation of $\mathrm{BC}$ has also been carried out in the worldwide monitoring stations of WMO/GAW (World Meteorological Organization/Global Atmosphere Watch) and numerous data have been obtained (Zheng et al., 2007). In China, BC from household stoves, coal combustion and ambient air in the Pearl River Delta, Beijing and other sites has been studied (Zhi et al., 2008; Li et al., 2009; Wu et al., 2009; Shen et al., 2010; Yan et al., 2010). In recent years, BC online concentration, possible emission sources and relationship with climate factors has been well reported based on a three-year monitoring at the QilianShan Station of Glaciology and Ecologic Environment (Zhao et al., 2012).

However, those macroscopic studies usually consider BC as a part of atmospheric particles, and detailed characteristics including morphology, textural properties, thermal stability of airborne BC are scarcely reported. Only BC particles collected from sediments and fly ash have been researched (Griffin and Goldberg, 1979; Stoffyn-Egli et al., 1997). Usually, it is difficult to separate BC from other atmospheric particles and also difficult to obtain enough $\mathrm{BC}$ for analysis. By contrast, in this study, atmospheric particles in a suburban site were sampled with a large volume sampler and for a long enough time to obtain sufficient sample volume, and then BC particles were isolated and characterized by physico-chemical methods. To further identify the possible sources, samples from mobile vehicle emission (including gasoline and diesel vehicles), and coal and biomass burning were also collected and analyzed. The aims of this study are to establish the major morphology and chemical characteristics of airborne BC and to identify their major sources at the sampling site.

\section{Materials and methods}

\subsection{Particle samples}

A high volume TSP (total suspended particles, diameter less than $100 \mu \mathrm{m}$ ) sampler (HV-1000F, Sibata Scientific Technology Ltd., Tokyo, Japan) was used to gather the data. The sampler was set at an approximate altitude of $16 \mathrm{~m}$, located on the roof of a building in the Research Center for Eco-Environmental Sciences (RCEES) in Beijing, China $\left(40^{\circ} 00^{\prime} \mathrm{N}\right.$ and $\left.116^{\circ} 20.240^{\prime} \mathrm{E}\right)$. More information about the sampling location was given in our previous study (Wang et al., 2009). Aerosol samples were collected once a week and every sampling lasted for $24 \mathrm{hr}$ at a flow rate of $1000 \mathrm{~L} / \mathrm{min}$. Quartz filters were used in the experiments (QR100, Advantec Corporation, Tokyo, Japan) with a collection efficiency of $99.99 \%$ for $0.3 \mu \mathrm{m}$ particles. Besides the airborne particles, samples were also collected from four main combustion sources. Vehicle emission particles were collected from the tail pipes of gasoline and diesel-powered vehicular internal combustion engines during normal tests. Particles from coal and biomass burning were collected from the top inner surface of the chimney in nearby household stoves.

\subsection{Pre-treatment and analysis}

As mentioned above, in most cases BC is mixed with other components in particles and its content is not so high that isolation and concentration of samples are necessary. There are methods for BC exaction from sediment samples. Generally, those methods consist of steps designed to eliminate carbonate, silicate minerals and organic matter, and the residue is regarded as $\mathrm{BC}$. The difference is that in some literature studies, $\mathrm{H}_{2} \mathrm{O}_{2} / \mathrm{KOH}$ was chosen for the oxidation of organic matter (Rose, 1990; Emiliani et al., 1991), and $\mathrm{K}_{2} \mathrm{Cr}_{2} \mathrm{O}_{7} / \mathrm{H}_{2} \mathrm{SO}_{4}$ was selected as the oxidation agent in other references (Wolbach and Anders, 1989; Lim and Cachier, 1996; Bird and Grocke, 1997). In this work, we chose the latter because dichromate has been shown to be the most effective for oxidizing organic matter with minimal effect on BC, including charred materials. For the samples from ambient air, particles were scraped carefully from the surface of the quartz filter, and then about four samples were mixed together for analysis at one time. The emission source samples were collected in the form of powder, so they were directly ready for analysis. All samples were treated following Lim's method.

A scanning electron microscope (SEM, S-4800, Hitachi, Tokyo, Japan) and a transmission electron microscope (TEM, H-7500, Hitachi, Tokyo, Japan) were employed to analyze the morphology of BC separated from the above samples. The SEM has an Energy Dispersive X-ray Spectrometer (EDX) attachment, which was used to measure the composition of BC particles. All samples were dispersed in ethanol, and deposited on a copper microgrid prior to the morphology observation.

A gas sorption analyzer (NOVA 2100, Quantachrome, Boynton Beach, Florid, US) was used to calculate the BET surface areas based on the linear part of the BET plot. The samples were all degassed under vacuum at $100^{\circ} \mathrm{C}$ for more than $4 \mathrm{hr}$ before the measurement. The total pore volumes were estimated according to nitrogen uptake at a relative pressure ratio of $0.99\left(\mathrm{P} / \mathrm{P}_{0}\right)$.

Based on the fact that BC from different sources could be oxidized at different temperatures, the temperature programmed oxidation (TPO) method was adopted to identify the possible oxidation stages of BC from different sources. TPO tests were carried out in a TPx analyzer (Chem 2720, Micromeritics, Norcross, GA, USA). During each test, a certain mass of BC was used $(20 \mathrm{mg})$, and the room temperature was raised to $1100^{\circ} \mathrm{C}$ under a gas flow of pure $\mathrm{O}_{2}(\geq 99.99 \%)$, with a heating rate of $10^{\circ} \mathrm{C} / \mathrm{min}$. 


\section{Results and discussion}

\subsection{Morphology of black carbon}

The morphologies of BC separated from different samples are shown in Fig. 1. It was found that BC from diesel emission particles (DEPs) aggregates into long chains and appears spherical, with a diameter less than $50 \mathrm{~nm}$ (Fig. 1a), smaller than that of diesel soot particles, which is about $100 \mathrm{~nm}$ (Murr and Soto, 2005). The morphology of BC from gasoline emission particles (GEP) gives the same trend as that of diesel BC particles, and also appears spherical with a diameter less than $50 \mathrm{~nm}$, but the aggregation is more pronounced than that of BC from DEP (Fig. 1b). BC from coal combustion particles (CCPs) is generally porous, but not always spherical (Fig. 1c), and the same conclusion was drawn in Stoffyn-Egli's study. These observations support the suggestion that the morphology of the spherical BC is influenced by the temperature and degree of combustion as well as the nature of the source material (Rose, 1990). Fig. 1d shows the image of BC from biomass burning particles (BBP), which is observed as blocks,

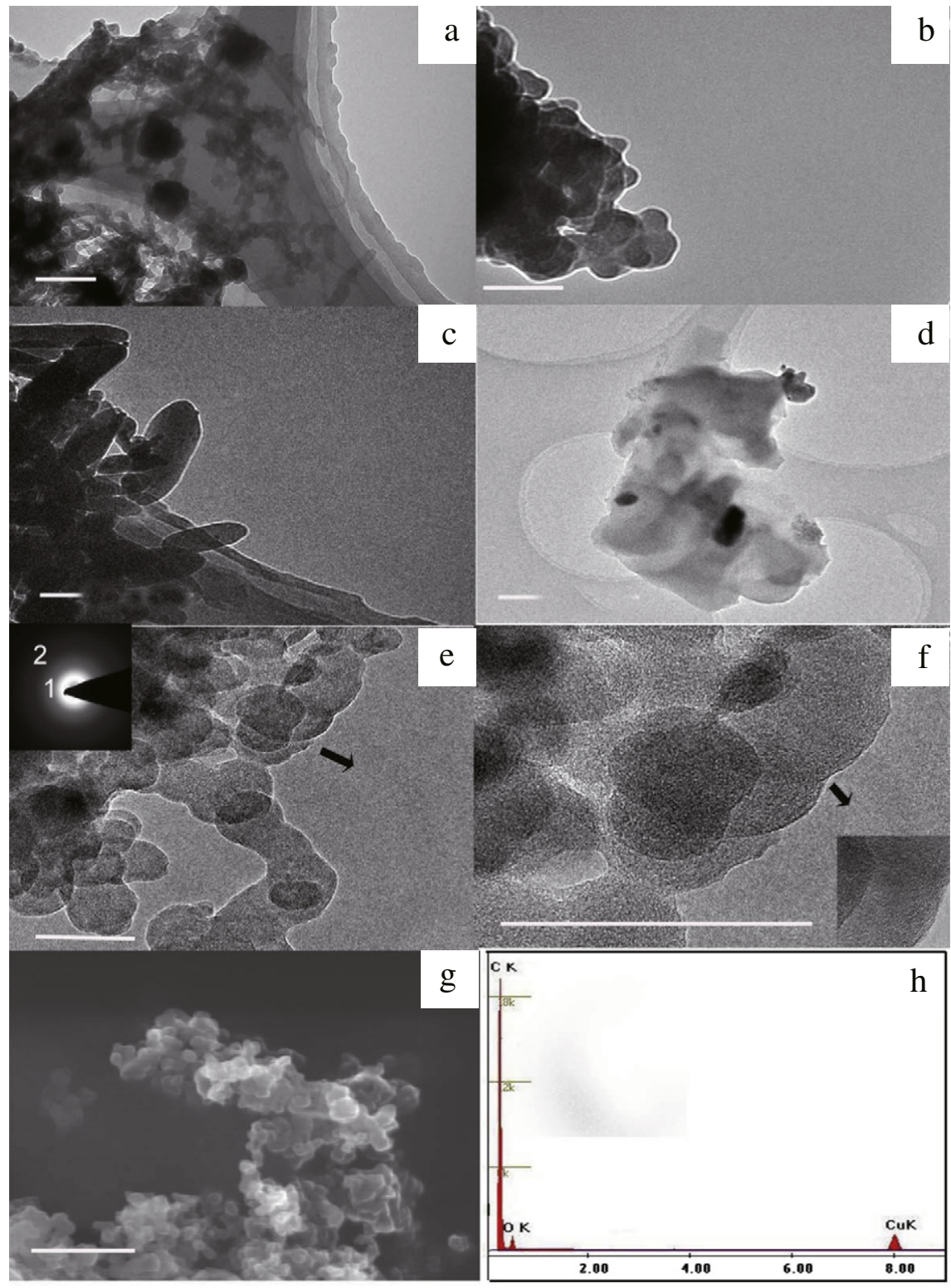

Fig. 1 - TEM and SEM images of BC examples from different samples. All scale bars represent 100 nm. Panels a-e represent BC from diesel emission particles (DEP), gasoline emission particles (GEP), coal combustion particles (CCP), biomass burning particles (BBP) and the atmospheric particles (TSP), respectively; SAED pattern inset in panel e shows the diffuse diffraction, and the rings 1 and 2 correspond to graphite (002) and (100), respectively; panel f represents a high magnification image of aggregated spherule-like carbon referred to the section of panel e and higher magnified section in panel $f$ referenced by open arrow; panel $g$ is the SEM image of BC from TSP samples; panel h shows EDX results of BC from TSP samples. 
with irregular fragments resembling those reported in the literature, suggesting that these BCs from biomass burning often exhibited plant-like structures such as pores or sides of tubular channels (Stoffyn-Egli et al., 1997).

The morphology of BC from atmospheric samples has so far been scantily reported. Ogren and Charlson suggest that the $\mathrm{BC}$ particles in the atmosphere show only a microcrystalline structure, tend to be spherical, are often agglomerated into 0.1-1 $\mu \mathrm{m}$ chains or $0.01-0.1 \mu \mathrm{m}$ agglomerates, and have no real image (Ogren and Charlson, 1983). Utsunomiy's study reports on nanometer-sized atmospheric carbonaceous matter of distributed sizes between 40 and $50 \mathrm{~nm}$. They identified these to be fullerenes by using the matrix-assisted laser desorption/ionization time-of-flight mass spectrometry technique (Utsunomiya et al., 2002). Our study indicates that most $\mathrm{BC}$ particles in the atmosphere are $50 \mathrm{~nm}$ spherical particles and they are easily aggregated (Fig. 1e-g). Fig. If shows a distinct surface regime, giving a uniformity of spherules ranging in diameter around $50 \mathrm{~nm}$ and creating a framboidal aggregate of mostly amorphous and very-short-range structure graphitic matter. To confirm if the $50 \mathrm{~nm} \mathrm{BC}$ spherical particles observed in this study have a microcrystalline structure, as suggested by the reference (Ogren and Charlson, 1983), we analyzed the BC particles using the selected area electron diffraction (SAED) pattern technique in the TEM test. The SAED patterns inset in Fig. 1e illustrate the generally amorphous microstructure of $\mathrm{BC}$, and no significant range of order to produce hexagonal lattice diffraction is observed correspondingly. The sizes and numbers of overlapping graphene sheets or fragments forming the primary carbon spherules might produce a perturbed or turbostratic structure. Fig. 1h shows the EDX results of $\mathrm{BC}$ from TSP samples; only $\mathrm{C}$ and $\mathrm{O}$ elements are observed ( $\mathrm{Cu}$ is observed due to the use of the copper microgrid), suggesting the pretreatment could successfully remove the inorganic components.

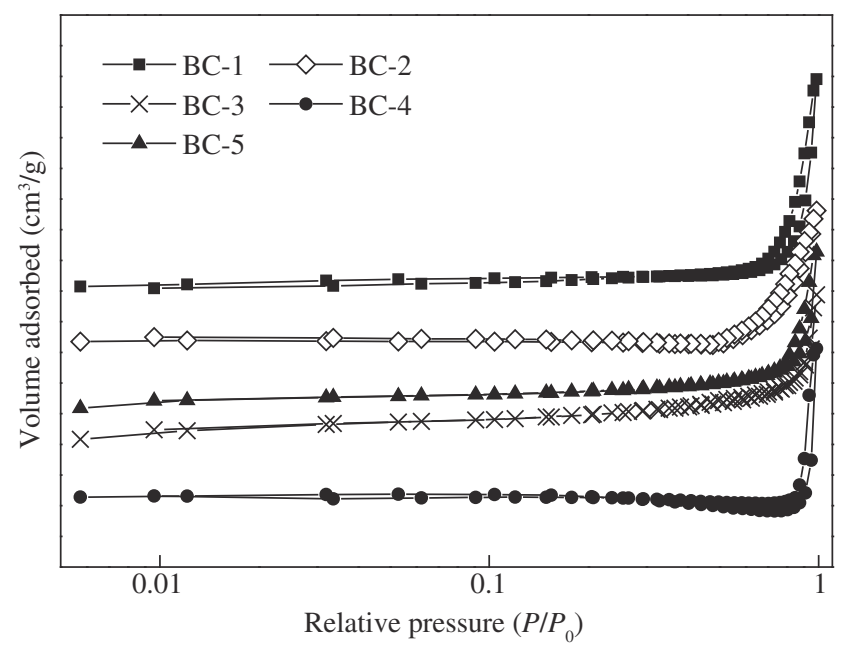

Fig. 2 - Nitrogen adsorption-desorption isotherms of black carbon (BC). BC-1, BC-2, BC-3, BC-4, and BC-5 represent BC extracted from DEP, GEP, CCP, BBP, and TSP samples, respectively.
Table 1 - Textural properties of black carbon (BC) particles.

\begin{tabular}{lccc} 
Sample & $\begin{array}{c}\text { BET surface } \\
\text { area }\left(\mathrm{m}^{2} / \mathrm{g}\right)\end{array}$ & $\begin{array}{c}\text { Total pore } \\
\text { volume }\left(\mathrm{cm}^{3} / \mathrm{g}\right)\end{array}$ & $\begin{array}{c}\text { Mean pore } \\
\text { diameter }(\mathrm{nm})\end{array}$ \\
\hline BC-1 & 8 & 0.05 & 17 \\
BC-2 & 8 & 0.03 & 12 \\
BC-3 & 23 & 0.04 & 7 \\
BC-4 & 3 & 0.04 & 53 \\
BC-5 & 12 & 0.04 & 13 \\
\hline
\end{tabular}

BC-1, BC-2, BC-3, BC-4, BC-5 represent BC extracted from diesel emission particles (DEP), gasoline emission particles (GEP), coal combustion particles (CCP), biomass burning particles (BBP) and the atmospheric particles (TSP), respectively.

\subsection{Textural properties of black carbon}

The nitrogen adsorption-desorption isotherms of the five types of BC are shown in Fig. 2. All the isotherms are of type III, suggesting the low adsorption of nitrogen on the BC particles (Sing et al., 1985). The nitrogen isotherms also exhibit a H1-type (38) hysteresis loop and feature a sharp step in the $P / P_{0}$ range of $0.7-1.0$; the sharpness of this step is indicative of the accumulation mode of BC particles and the uniformity of the pore size. Quantitative data on textural properties are shown in Table 1. BC from the DEP and GEP samples shows similar data for surface area (both are $8 \mathrm{~m}^{2} / \mathrm{g}$ ), total pore volume $\left(0.05 \mathrm{~cm}^{3} / \mathrm{g}\right.$ for BC from DEP and $0.03 \mathrm{~cm}^{3} / \mathrm{g}$ for BC from GEP) and mean pore diameters (17 $\mathrm{nm}$ for $\mathrm{BC}$ from DEP and $12 \mathrm{~nm}$ for BC from GEP). On the contrary, the data for BC from CCP and BBP samples are different, with BC from BBP samples having much larger mean pore diameter (53 nm) and relatively smaller surface area $\left(3 \mathrm{~m}^{2} / \mathrm{g}\right)$, which might be related to their irregular morphology and large particle size. Researchers have pointed out that the particle structure depends upon fuel identity, temperature of combustion, and combustion kinetics and chemistry (Greico et al., 2000; Vander Wal and Tomasek, 2004). It should be mentioned that the data of BC from the atmospheric particles (TSP) are closer to those of BC from the DEP and GEP samples in terms of BET surface area and mean pore diameter, which are $12 \mathrm{~m}^{2} / \mathrm{g}$ and $13 \mathrm{~nm}$, respectively, than $\mathrm{BC}$ from other combustion sources.

\subsection{Results of $\mathrm{O}_{2}$-TPO tests}

Usually, the oxidation of carbon particles is generally divided into three stages, namely, dehydration, solvent organic fraction oxidation at low temperature and solid carbon oxidation at high temperature. In Fig. 3, the oxidation temperature of BC from TSP samples can be seen to be in the range of $406-490^{\circ} \mathrm{C}$ (curve a). Usually, the oxidation temperature of organic carbon (OC) is below $450^{\circ} \mathrm{C}$. Thus, it appears that the removal of organic matter in the pre-treatment steps was not complete and organic matter still remained in samples. In fact, in conventional thermal measurements, the oxidation is usually carried out in a $8 \%-10 \% \mathrm{O}_{2}$ atmosphere. However, in our work, with the aim of complete oxidation of $\mathrm{BC}$, experiments were done in an oxygen-enriched atmosphere with $\mathrm{O}_{2} \geq 99.99 \%$. According to the oxygen enriched combustion (OEC) theory, combustion is triggered by high energy collisions between oxygen and 


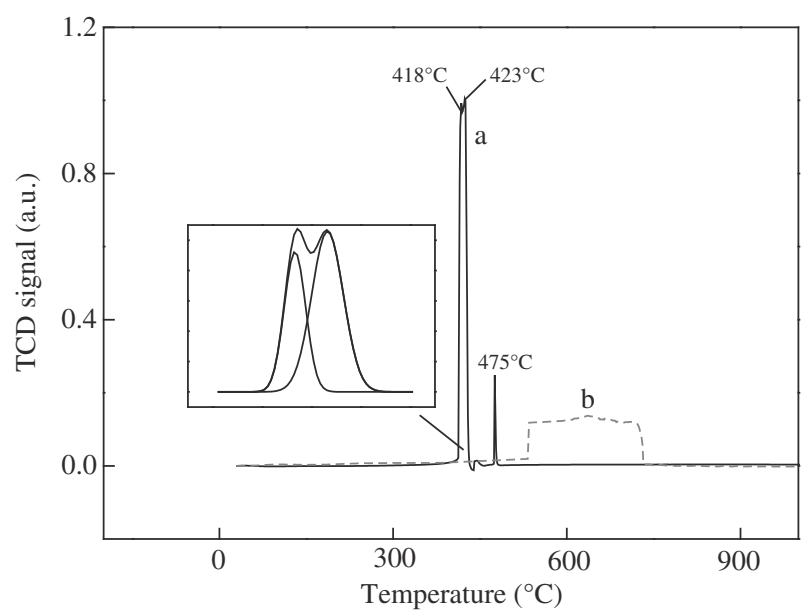

Fig. 3 - TPO profiles of black carbon (BC) sample (BC-5). (line a) oxidation with pure $\mathrm{O}_{2}$; (line b) The inset plot shows the fitting of the highest peak in curve a.

combustible molecules, and thus the oxygen delivery efficiency directly affects the ignition temperature, combustion rate, and combustion products etc. In this study, oxygen and BC have adequate contact under the pure oxygen atmosphere, and thus the ignition temperature might be lower. To prove our hypothesis, the experiment was also carried out in an air atmosphere under the same conditions, and the oxidation temperature was found to exceed $450^{\circ} \mathrm{C}$, falling in the range of $534-730^{\circ} \mathrm{C}$ (curve b), indicating that the removal of OC is complete in the treatment steps. Generally, the oxidation profile of BC from TSP samples gives clear oxidation stages, with peaks at 418,423 and $475^{\circ} \mathrm{C}$, respectively. The temperature difference between the first and the third peak is about $50^{\circ} \mathrm{C}$. Thus, these oxidation stages could be classified as the same type: solid carbon oxidation, regarded as oxidation of amorphous carbon (Peng et al., 2005).

The $\mathrm{O}_{2}$-TPO profiles of $\mathrm{BC}$ samples from combustion sources are shown in Fig. 4. The oxidation peaks of $B C$ from CCP and BBP samples are at 444 and $435^{\circ} \mathrm{C}$, although they derive from different combustion processes. Meanwhile, the $\mathrm{O}_{2}$-TPO profile of $\mathrm{BC}$ from DEP samples was obviously different from that of GEP samples, with the $\mathrm{O}_{2}$-TPO profile of BC from GEP samples showing a single peak at $404^{\circ} \mathrm{C}$, while the $\mathrm{O}_{2}$-TPO profile of $\mathrm{BC}$ from GEP samples yields three oxidation peaks, appearing at 405,408 , and $467^{\circ} \mathrm{C}$, respectively. When compared with the profiles of BC from TSP and DEP samples, the profiles are relatively similar: oxidation stages are characterized by three peaks and the positions of the oxidation peaks are close. For BC from TSP samples, the oxidation peaks are at 418,423 and $475^{\circ} \mathrm{C}$, while for $\mathrm{BC}$ from DEP samples, the oxidation peaks are at 405,408 , and $467^{\circ} \mathrm{C}$.

\subsection{Primary black carbon source tracking}

As mention previously, our sampling site RCEES lies at a suburban site (a downtown village could be seen on the west side, which is now under construction) and is located at the intersection of two busy roads. As is known, BC usually come

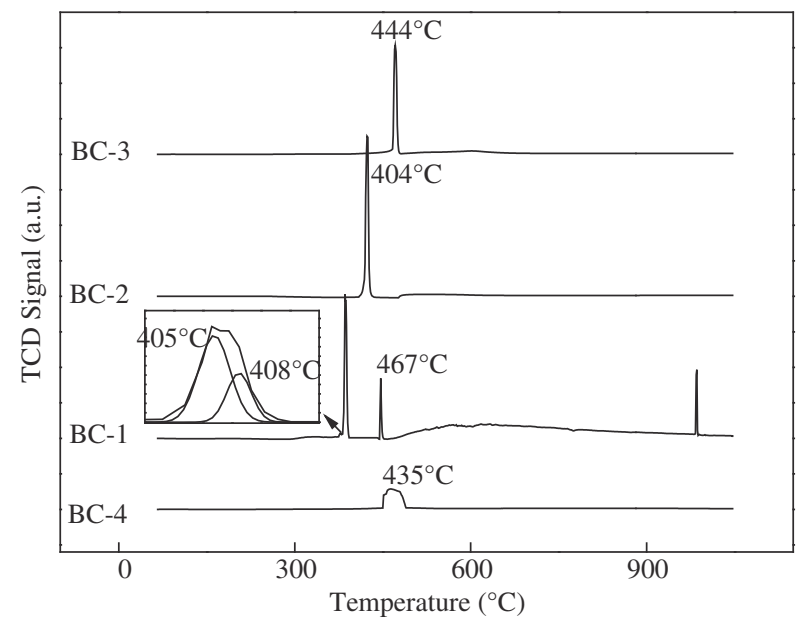

Fig. 4 - TPO profiles of black carbon (BC) samples. The inset plot shows the fitting of the highest peak in curve BC-1. 
from vehicle emissions and combustion of coal, biomass burning etc. In this work, bus, light and heavy trucks fed with diesel could be observed as frequently as gasoline vehicles. Usually, BC emission from diesel vehicles is much higher than that from gasoline vehicles (Liu and Shao, 2007; Qin and Xie, 2012), and the situation might be even worse under poor operation characterized by the narrow and crowded road conditions in this work. So, it is proposed that diesel vehicle emission is a major source of BC. Besides vehicle emissions, coal and biomass combustion could also be seen in the downtown village. However, the ratio will continue to be decreased due to the re-construction and coal will be completely replaced by natural gas in the coming future. Biomass burning could be neglected due to the rather small ratio (biomass burning by using wood or agriculture residue is occasionally seen and it is difficult to obtain the BBP samples). Based on the morphology, BET and $\mathrm{O}_{2}$-TPO analysis results and source analysis, we conclude that the airborne BC in this area mainly comes from diesel vehicle emissions.

\section{Conclusions}

Particles from the atmosphere as well as from vehicle emission, coal combustion and biomass burning were collected, and BC was separated and isolated by chemical methods. EDX and $\mathrm{O}_{2}$-TPO results indicate that inorganic elements and organic carbon were successfully removed during the pre-treatment processes. TEM results indicate that BC emitted from different sources shows various patterns including spherical, elliptical and irregular shapes. As for airborne BC, it appears to be spherical and about $50 \mathrm{~nm}$ in diameter, with a homogeneous surface and turbostratic structure, and is easily aggregated. The BET (Barrett-Emmett-Teller) analysis shows that BC particles are of accumulation mode and have uniform pore size. The surface area and the average pore diameter of BC from TSP samples are $12 \mathrm{~m}^{2} / \mathrm{g}$ and $13 \mathrm{~nm}$, which are much closer to the values of $\mathrm{BC}$ from vehicle emission; meanwhile, the textural properties of BC from coal and biomass burning are obviously different from $\mathrm{BC}$ derived from vehicle emission. $\mathrm{O}_{2}$-TPO profiles of $\mathrm{BC}$ from gasoline vehicle emission, coal combustion and biomass burning are characterized by a single peak. $\mathrm{O}_{2}$-TPO profiles of BC from TSP and diesel vehicle emission are very similar in that two stages with three peaks are observed for both samples. The oxidation peaks of BC from TSP samples are observed at 418,423 and $475^{\circ} \mathrm{C}$, and the oxidation peaks of BC from DEP occur at 405,408 , and $467^{\circ} \mathrm{C}$. Both are classified as amorphous carbon oxidation.

Based on the analysis of the sampling site, variation tendencies of source emission and the experimental results, the conclusion is drawn that diesel vehicle emission is the major source of BC at this suburban site.

\section{Acknowledgments}

This work was supported by the Key project for Beijing Municipal Science and Technology Plan (No. D131100003613002) and the Open Project from Jiangsu Key Laboratory of Atmospheric Environment Monitoring and Pollution Control of Nanjing
University of Information Science and Technology (KHK1108), the Jiangsu Province Innovation Platform for Superiority Subject of Environmental Science and Engineering.

\section{REFERENCES}

Alfaro, S.C., Comes, L., Rajot, J.L., Lafon, S., Gaudichet, A., Chatenet, B., et al., 2003. Chemical and optical characterization of aerosols measured in spring 2002 at the ACE-Asia super site, Zhenbeitai, China. J. Geophys. Res. 108 (D23). http://dx.doi.org/ 10.1029/2002JD003214.

Bird, M.I., Grocke, D.R., 1997. Determination of the abundance and carbon isotope composition of elemental carbon in sediments. Geochim. Cosmochim. Acta 61 (16), 3413-3423.

Cachier, H., Bremond, M.P., BuatMenard, P., 1988. Atmospheric soot carbon over the ocean. Chem. Geol. 70 (1-2), 96.

Chylek, P., Johnson, B., Wu, H., 1992. Black carbon concentration in a Greenland DYE-3 ice core. Geophys. Res. Lett. 19 (19), 1951-1953.

Decesari, S., Facchini, M.C., Matta, E., Mircea, M., Fuzzi, S., Chughtai, A.R., et al., 2002. Water soluble organic compounds formed by oxidation of soot. Atmos. Environ. 36 (11), 1827-1832.

Emiliani, C., Price, D.A., Seipp, J., 1991. Is the post glacial artificial? Geochem. Soc. Spec. Publ. (3), 229-231.

Greico, W.J., Howard, J.B., Rainey, L.C., Vander Sande, J.B., 2000. Fullerenic carbon in combustion-generated soot. Carbon 38 (4), 597-614.

Griffin, J.J., Goldberg, E.D., 1979. Morphologies and origin of elemental carbon in the environment. Science 206 (4418), 563-565.

Hansen, J., Sato, M., Ruedy, R., Lacis, A., Oinas, V., 2000. Global warming in the twenty-first century: an alternative scenario. Proc. Natl. Acad. Sci. U. S. A. 97 (18), 9875-9880.

Jacobson, M.Z., 2002. Strong radiative heating due to the mixing state of black carbon in atmospheric aerosols. Nature 409 (6821), 695-697.

Lelieveld, J., Crutzen, P.J., Ramanathan, V., Andreae, M.O., Brenninkmeijer, C.A.M., Campos, T., et al., 2001. The Indian Ocean experiment: widespread air pollution from South and Southeast Asia. Science 291 (5506), 1031-1036.

Li, X.H., Wang, S.X., Duan, L., Hao, J.M., Nie, Y.F., 2009. Carbonaceous aerosol emissions from household biofuel combustion in China. Environ. Sci. Technol. 43 (15), 6076-6081.

Lim, B., Cachier, H., 1996. Determination of black carbon chemical oxidation and thermal treatment in recent marine and Lake sediments and Cretaceous-Tertiary clays. Chem. Geol. 131 (1-4), 143-154.

Liu, Y., Shao, M., 2007. Estimation and prediction of black carbon emissions in Beijing City. Chin. Sci. Bull. 52 (9), 1274-1281.

Lohrnann, R., MacFarlane, J.K., Gschwend, P.M., 2002. Importance of black carbon to sorption of native PAHs, PCBs and PCDDs in Boston and New York, Harbor sediments. Environ. Sci. Technol. 39 (1), 141-148.

Menon, S., Hansen, J., Nazarenko, L., Luo, Y.F., 2002. Climate effects of black carbon aerosols in China and India. Science 297 (5590), 2250-2253.

Murr, L.E., Soto, K.F., 2005. A TEM study of soot, carbon nanotubes, and related fullerene nanopolyhedra in common fuel-gas combustion sources. Mater. Charact. 55 (1), 50-65.

Ogren, J.A., Charlson, R.J., 1983. Elemental carbon in the atmosphere: Cycle and lifetime. Tellus B 35B (4), 241-254.

Peng, F., Wang, H.J., Yu, H., Feng, J.X., 2005. Study on oxidation kinetics of carbon nano tubes by temperature programmed oxidation. Petrochem. Technol. 34 (11), 1064-1067.

Qin, Y., Xie, S.D., 2012. Spatial and temporal variation of anthropogenic black carbon emissions in China for the period 1980-2009. Atmos. Chem. Phys. 12 (11), 4825-4841. 
Richter, L., Howard, J.B., 2000. Formation of polycyclic aromatic hydrocarbons and their growth to soot-a review of chemical reaction pathways. Prog. Energy Combust. Sci. 26 (4-6), 565-608.

Rose, N.L., 1990. A method for the extraction of carbonaceous particles from lake sediment. J. Paleolimnol. 3 (1), 45-53.

Rose, N.L., 1995. Carbonaceous particle record in lake sediments from the Arctic and other remote areas of the Northern-Hemisphere. Sci. Total Environ. 160-161, 487-496.

Shen, G., Yang, Y., Wang, W., Tao, S., Zhu, C., Min, Y., et al., 2010. Emission factors of particulate matter and elemental carbon for crop residues and coals burned in typical household stoves in China. Environ. Sci. Technol. 44 (18), 7157-7162.

Sing, K.S.W., Everett, D.H., Haul, R.A.W., Moscou, L., Pierotti, R.A., Rouquerol, J., et al., 1985. Reporting physisorption data for gas/solid systems. Pure Appl. Chem. 57 (4), 603-619.

Stoffyn-Egli, P., Potter, T.M., Leonard, J.D., Pocklington, R., 1997. The identification of black carbon particles with the analytical scanning electron microscope: methods and initial results. Sci. Total Environ. 198 (3), 211-223.

Utsunomiya, S., Jensen, K.A., Keeler, G.J., Ewing, R.C., 2002. Uraninite and fullerene in atmospheric particulates. Environ. Sci. Technol. 36 (23), 4943-4947.

Vander Wal, R.L., Tomasek, A.J., 2004. Soot nanostructure: dependence upon synthesis conditions. Combust. Flame 136 (1-2), 129-140.

Wang, H.L., Zhou, Y.M., Zhuang, Y.H., Wang, X.K., Hao, Z.P., 2009. Characterization of $\mathrm{PM}_{2.5} / \mathrm{PM}_{2.5-10}$ and source tracking in the juncture belt urban and rural areas of Beijing. Chin. Sci. Bull. 54 (14), 2506-2515.
Wolbach, W.S., Anders, E., 1989. Element carbon in sediments: determination and isotopic analysis in the presence of kerogen. Geochim. Cosmochim. Acta 53 (7), 1637-1647.

Wu, D., Mao, J.T., Deng, X.J., Tie, X.X., Zhang, Y.H., Zeng, L.M., et al., 2009. Black carbon aerosols and their radiative properties in the Pearl River Delta region. Sci. China Ser. D Earth Sci. 52 (8), 1152-1163.

Yan, P., Liu, G.Q., Zhou, X.J., Wang, J.L., Tang, T., Liu, Q., et al., 2010. Characteristics of aerosol optical properties during haze and fog episodes at Shangdianzi in northern China. J. Appl. Meteorol. Sci. 21 (3), 257-265.

Yang, Y.N., Sheng, G.Y., 2003a. Pesticide adsorptivity of aged particulate matter arising from crop residue burns. J. Agric. Food Chem. 51 (17), 5047-5051.

Yang, Y.N., Sheng, G.Y., 2003b. Enhanced pesticide sorption by soils containing particulate matter from crop residue burns. Environ. Sci. Technol. 37 (16), 3635-3639.

Yang, Y.N., Chun, Y., Sheng, G.Y., Huang, M.S., 2004. pH-dependence of pesticide adsorption by wheat-residue-derived black carbon. Langmuir 20 (16), 6736-6741.

Zhao, S.Y., Ming, J., Xiao, C.D., Sun, W.J., Qin, X., 2012. A preliminary study on measurements of black carbon in the atmosphere of northwest Qilian Shan. J. Environ. Sci. 24 (1), 152-159.

Zheng, A.Q., Su, Y.X., Zhao, J.D., 2007. Review on black carbon aerosol. Energy Environ. Protect. 21 (5), 4-8.

Zhi, G.R., Chen, Y.J., Feng, Y.L., Xiong, S.C., Li, J., Zhang, G., et al., 2008. Emission characteristics of carbonaceous particles from various residential coal-stoves in China. Environ. Sci. Technol. 42 (9), 3310-3315. 